International Journal of

Health Sciences

(IJHS)

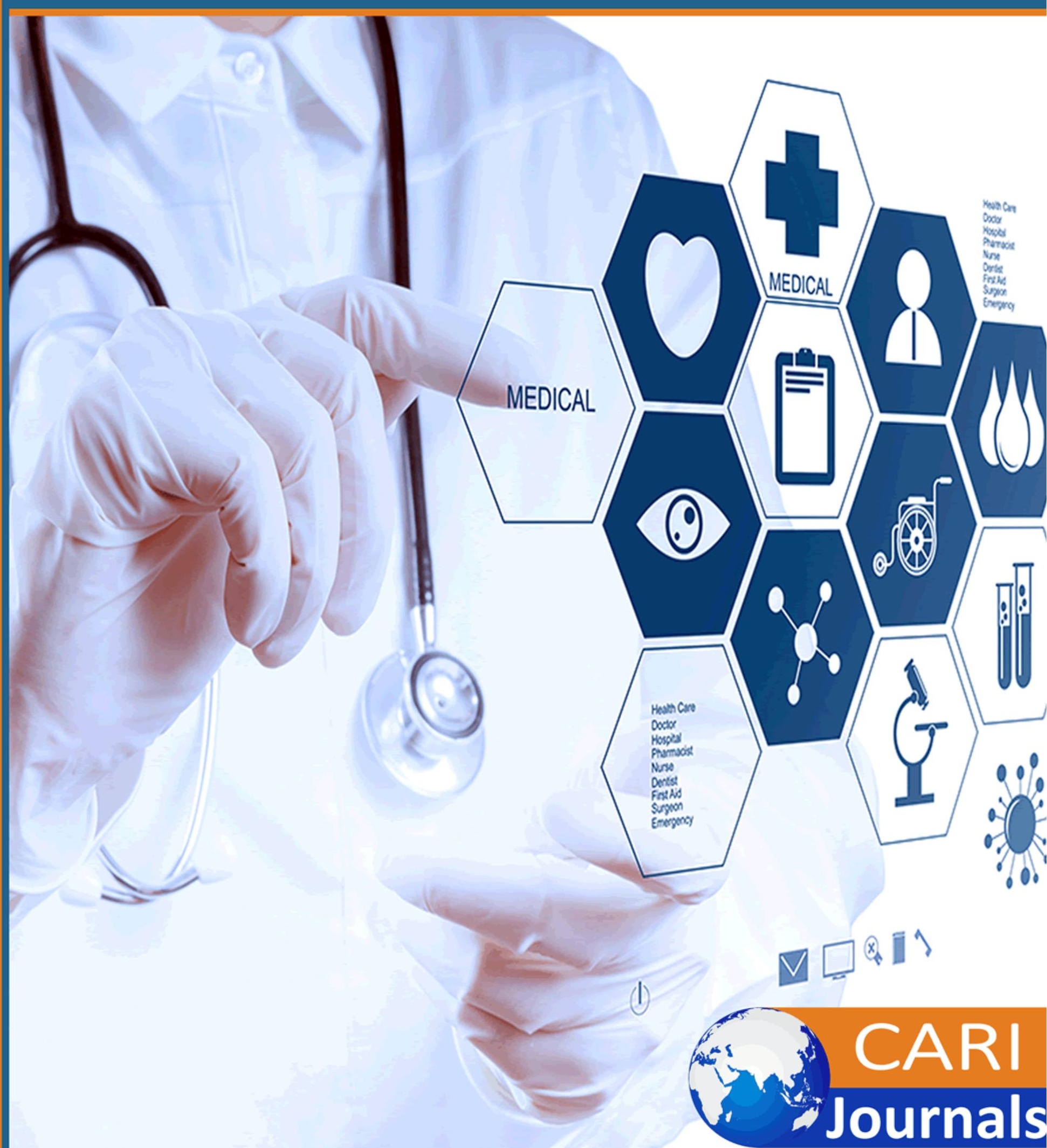




\title{
FIRST LINE ANTI-RETRO VIRAL DRUGS DISRUPTS THE ESTRUS CYCLE OF WISTAR RATS
}

\author{
$1^{*}$ Dr Aigbe Gregory Ohihoin, \\ Nigerian Institute of Medical Research; Edmund crescent, Yaba, Lagos. \\ *Corresponding Email: aigbe.ohihoin@yahoo.com
}

\begin{abstract}
Background: Patients with HIV AIDS are beginning to live longer and healthier lives due to the use of ARV therapy. The effect of long term usage of these agents on the reproductive potential of human females has not been well studied. The study of the estrus cycle in rats will give information on the possible effect of ARV's on the reproductive potential of humans.
\end{abstract}

Aims: To elucidate the effects of the first-line ARV's, Efavirenz, Tenofovir and Lamivudine administered in a combined fashion, on the oestrous cycle of adult female Wistar rats.

Material and Methods: Twenty-five female Wistar rats with a mean weight of $158.76 \mathrm{~g}$ were used. A total of five groups of rats were involved in the study. Five rats were apportioned to each study group. All three ARV's were administered orally in a combined fashion to a particular group of Female Wistar rats and also administered individually to other groups while the control group received water. The estrous cycles of various groups of rats were monitored via microscopic analysis of their vaginal smears

Results: The control group had a consistently regular cycle, while the cycles of the rats in the combination therapy group and the rats that received efavirenz alone, became elongated relative to the control group. There was a 48-hour enlongated proestrous phase some of the rats.

Conclusions: First-line ARV's - Tenofovir, Efavirenz, and Lamivudine- disrupt the estrous cycle of adult rats. Further investigation of the long term usage of these drugs on the menstrual cycle of human females is therefore necessary

Key-words: antiretroviral, disrupt, cycle

Key Messages: Use of ARV's alters rat's estrous cycle; long-term use of ARV's may affect human menstrual pattern 


\section{INTRODUCTION}

Patients with HIV AIDS now live healthily longer due to use of ARV's. ${ }^{[1]}$ Evidence suggests that the life expectancy of patients who are well managed for HIV infection are not so different from their HIV negative counterparts. ${ }^{[1,2]}$ The oestrous cycle in the wistar rats mirrors the changes in the menstrual cycle in humans. Exploring the effect of ARV's on the oestrous cycle of the rats could explain the influence on their reproductive functions and provide useful information in the study of HIV positive women who are receiving ARV's. Thus, this was to elucidate the effects of the first-line ARV's, Efavirenz, Tenofovir and Lamivudine administered in a combined fashion, on the oestrous cycle of adult female Wistar rats.

\section{MATERIAL AND METHODS}

A total of 25 female wistar rats weighing about $150 \mathrm{~g}$ to $170 \mathrm{~g}$ were obtained and kept in the experimental animal house of the Nigerian Institute of Medical Research (NIMR). They were kept in a clean cage at a temperature of about $28 \mathrm{oC}$. The animals were kept in accordance to conditions stipulated by the U.S National Institute of Health (NIH) involving a cycle of 12 hours light and dark. The laboratory animals were allowed two weeks to acclimatize to their new environment; thereafter the animals were apportioned in a random manner with five animals in each group in the following manner: Group 1: (Control) This group was given water; Group 2: This group received Efavirenz. The dosage was $9 \mathrm{mg} / \mathrm{kg}$ body weight through a vehicle of water; Group 3: This group was given Tenofovir. The administered dosage was $4.5 \mathrm{mg} / \mathrm{kg}$ body weight through a vehicle of water; Group 4: This group was given Lamivudine at a dosage of $4 \mathrm{mg} / \mathrm{kg}$ body weight through a vehicle of water; Group 5: This group received a combination of Efavirenz, Tenofovir and Lamivudine as a Fixed dose Combination. The dose combination Tenofovir $4.5 \mathrm{mg} / \mathrm{kg}$ body weight, Efavirenz $9 \mathrm{mg} / \mathrm{kg}$ body weight and Lamivudine $4 \mathrm{mg} / \mathrm{kg}$ body weight in a fixed dose combination through a vehicle of water. The experimental animals received daily treatment through a cannula for a period of four weeks.

\section{DETERMINATION OF PHASES OF THE OESTROUS CYCLE}

The procedure involved the use of a dropper that was rinsed in distilled water and used to obtain 10mls of normal saline. The dropper with normal saline was carefully inserted into the vagina of the rats to express the vagina fluid. The vagina fluid was subsequently placed on a slide for the purpose of observation under the light microscope using the $\mathrm{x} 40$ magnification. The smears were evaluated for the characteristic cell type and used for the identification of the various phases of the oestrous cycle. Dominance of leukocytes in the smear was indicative of dioestrus phase, while the dominance of nucleated epithelial cells indicated proestrous. Presence of cornified epithelial cells along with some cell debris in the smear was indicative of oestrous. The metestrus is reflective of mixed leucocyte and cornified cells.

\section{PROCEDURE FOR DRUG ADMINISTRATION}

The experimental animals received antiretroviral drugs effavirenz, tenofovir and Lamivudine at measured doses for weight, for a period of four weeks.

LAMIVUDINE (3TC) Brand used: Mylan 150mg film coated oral tablet.

Predicted solubility of Lamivudine is $2.76 \mathrm{mg} / \mathrm{ml}$ which is approx $3 \mathrm{mg} .^{3}$ Therefore, 1 tablet was dissolved in $100 \mathrm{ml}$ of distilled water to form a $0.3 \mathrm{mg} / \mathrm{ml}$ solution The tablet was crushed in a porcelain mortar and rinsed into a conical flask A $2 \mathrm{ml}$ oral syringe was used to administer the appropriate dose to 
the rat. Administered dose $=4 \mathrm{mg} / \mathrm{kg}(0.2 \mathrm{mg} / 50 \mathrm{~g}$ body weight $)$ Thus $0.75 \mathrm{ml}$ of $0.3 \mathrm{mg} / \mathrm{ml}$ solution was administered to a rat weighing approx $150 \mathrm{~g}$.

EFAVIRENZ Brand used: Strides 200mg film coated oral tablets

The half tablet was crushed in a porcelain mortar and rinsed into a conical flask Administered dose $=$ $9.0 \mathrm{mg} / \mathrm{kg}(0.45 \mathrm{mg} / 50 \mathrm{~g}$ body weight $)$ Thus $2.5 \mathrm{ml}$ of $0.18 \mathrm{mg} / \mathrm{ml}$ solution was given to a rat weighing approx $150 \mathrm{~g}$ NB The solution was shaken very well before withdrawal with syringe to ensure uniformity of dose. ${ }^{4}$

TENOFOVIR Brand used: Mylan 300mg film coated oral tablet

The 300mg tablet which is scored was split with a tablet cutter; the resulting half tablet was again split to form a quarter tablet The quarter tablet was crushed in a porcelain mortar and rinsed into a conical flask Administered dose $=4.5 \mathrm{mg} / \mathrm{kg}(0.22 \mathrm{mg} / 50 \mathrm{~g}) 1.1 \mathrm{ml}$ of $0.04 \mathrm{mg} / \mathrm{ml}$ solution was given to a $150 \mathrm{~g}$ rat Statistical Methods:

The statistical package for social sciences (SPSS) version 22 was used for statistical analysis. The results obtained were expressed in descriptive statistics using mean and standard deviations.

\section{RESULTS:}

\section{BODY WEIGHTS OF RATS IN THE STUDY GROUPS AND CONTROL}

The average weight of the rats in the study groups and control group before and after the administration of the anti-retroviral drugs is shown in the table below. The average weights of the rat remained fairly consistent before and after administration of the anti-retroviral agents.

Table 1: Body weights of rats in the study groups and control

\section{GROUP BEFORE AFTER CHI-SQUARE P-VALUE}

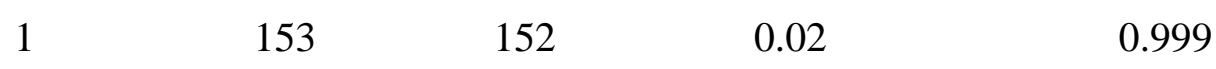

$2 \quad 160 \quad 162$

$3 \quad 140 \quad 140$

$4 \quad 156 \quad 157$

$5 \quad 156 \quad 155$

Table 2: Average duration of proestrous phase across groups

\begin{tabular}{|l|l|l|l|}
\hline GROUP & MEAN & STD. DEVIATION & STD. ERROR \\
\hline ONE & 0.85 & 0.548 & 0.316 \\
\hline
\end{tabular}




\begin{tabular}{|l|l|l|l|}
\hline TWO & 2.25 & & \\
\cline { 1 - 2 } FIVE & 2.25 & & \\
\hline
\end{tabular}

The table above shows the prolongation of the proestrous phase of the rats in groups 2 and 5 when compared to group 1

The proestrous phase of the oestrous cycle of the rats that received efavirenz had an average duration of 2.25days as against the normal average of 0.85 days The proestrous phase of the oestrous cycle of rats that received a combination of efavirenz, Lamivudine and tenofovir was also 2.25 days.

\section{Discussion:}

This study revealed that there was prolongation of the proestrous phase of the cycle. This is reflected as persistence of the proestrous cycle beyond 12 hours extending to as much as 72 hours in some cases. The average duration of proestrous is 12 hours. ${ }^{[6]}$ According to Andrews and Ojeda, the average duration of the oestrous cycle of the rat is 4.8 days. This duration is sub-divided into proestrous with a duration of 12-14 dyas. Oestrous with a duration of 25-27 hours, metestrous with a duration of 6-8 hours while diestrous will average a duration of 55-57 hours. In this study, there was a a prolongation of the proestrous phase in 4 out of the 5 rats that received a combination of lamivudine. Effavirenz and tenofovir. This gave a prolongation of the proestrous in $80 \%$ of the rats in study group, (group 5) that received a combination of this medication. In the control group, only $20 \%$ of the rats in that group had prolongation of the oestrous phase beyond 24 hours. It is worthy of note that the prolongation of the proestrous phase of the menstrual cycle, occurred mainly in the second week of study of the oestrous cycle after the administration of the drug. The possible reason for this may be that the effect of the anti retroviral medication on the oestrous cycle results from cummlative accumulation of the medication over a period of time following prolong usage. Prolongation of the proestrous phase of the cycle was also seen in study group 2 that received efavirenz. This finding thus suggest that efavirenz is the culprit in the distortion of the oestrous cycle in the rats, as there was only slight variation of the oestrous cycle in the other study groups receiving Lamivudine and Tenofovir alone. Concerns have been raised among patients with HIV over menstrual irregularities, there has been no research separating the effect of the disease from the effect of the drug. ${ }^{[7]}$ Earlier it was thought that the weight changes experienced by HIV positive patients may have accounted for the menstrual irregularities experienced by them. ${ }^{[8,9]}$ This postulation is no longer valid as the advent of highly active anti-retroviral therapy has improved the health conditions of patients and it is now observed that general wellbeing of HIV positive individuals is not different from their HIV counterpart. ${ }^{[10]}$ The prolongation of proestrous phase of the cycle in some of the rats meant that oestrous phase was absent in them. Absence of oestrous phase has reproductive implications for the rat as there is a surge in FSH and LH during oestrous leading to ovulation. ${ }^{\text {[11] }}$ Absence of the oestrous phase of the cycle will interfere with the process of ovulation, leading to anovulation and subsequent compromise in fertility. 


\section{References}

1. Johnson, L., Mossong, J., Dorrington, R., Schomaker, M., Hoffmann, C., Keiser, O., Fox, M., Wood, R., Prozesky, H., Giddy, J., Garone, D., Cornell, M., Egger, M., Boulle, A. (2013). Life expectancies of South African adults starting antiretroviral treatment: collaborative analysis of cohort studies. PLoS Med.;10:e1001418

2. Nakagawa, F., May, M., Phillips, A. (2013). Life expectancy living with HIV: recent estimates and future implications. Curr Opin Infect Dis.26:17-25

3. www.drudbank.can/drugs/DB00709

4. Smita Kolhe, Dr. Praveen Chaudhari, Dhananjay et al (2013) "Dissolution Enhancement of Poorly Water Soluble Efavirenz by Hot Melt Extrusion Technique” Int. J. Drug Dev. \& Res., , 5(2): 368-381. doi: doi

5. www.aidsreagent.org/reagentdetail

6. Andrews, WW, Ojeda, SRA. (1981). detailed analysis of the serum LH secretory profiles of conscious free-moving female rats during the time of pubertyEndocrinology. 109203239 available on https://www.ncbi.nlm.nih.gov/pubmed/6263582 accessed 09/12/17

7. Warne PA, Ehrhardt A, Schechter D, Williams J, Gorman J.(1991) Menstrual abnormalities in HIV+ and HIV- women with a history of intravenous drug use (abstract M. C. 311). VII International Conference on AIDS; Florence, Italy

8. U.S. Centers for Disease Control and Prevention.(1995) HIV/AIDS surveillance report. . pp. 1-34

9. Muggiasca ML, Agarossi A, Ghetti E, Ravasi L, Federici D, Conti M. (1993) Gyneacological problems in HIV-positive women (abstract PO-B23-1941). IX International Conference on AIDS; Berlin, Germany.

10. Cejtin, E., Kalinowski, A., Bacchetti, P., Taylor, R., Watts, D., Kim, S., Massad, L., Preston-Martin, S., Anastos, K., Moxley, M., Minkoff, H. (2006). Effects of human immunodeficiency virus on protracted amenorrhea and ovarian dysfunction. Obstet Gynecol.;108:1423-1431

11. Marcondes, f. k., Miguel, k., Melo, 1. 1. \& Spadari-bratfisch, R. C., 2001, Estrous cycle influences the response of female rats in the elevated plus-maze. Physiol. Behav., 74(4-5): 435-440 Acknowledgement: We acknowledge Oba Rasheed and Dr. Oladele for their data management effort. 